\title{
How Women Cope: Being a Numerical Minority in a Male-Dominated Profession
}

\author{
Laura Smart Richman* and Michelle vanDellen \\ Duke University
}

\section{Wendy Wood \\ University of Southern California}

Women who have academic careers in engineering have successfully navigated the social identity threats that prevent many other women from feeling that they belong in science, technology, engineering, and math fields. In this research, we examined what factors may be related to resilience in these academic environments. Female academics in engineering and nonengineering fields watched a fictitious conference video depicting either an unbalanced ratio of men to women or a balanced ratio. Subjective measures of identity threat were collected. Past experience with discrimination, positive experience with female role models, family support, and general social support were associated with a greater sense of belonging to or desire to participate in the conference. These variables all buffered negative responding to social identity threat. Implications are discussed for understanding resilience to social identity threat, particularly among women in engineering.

Women in the United States and other industrialized nations increasingly are entering traditionally male fields of study, employment, and athletic competition (Wood \& Eagly, in press). This remarkable social change is evident especially in engineering and math-intensive science fields. For example, women in 1958 earned less than $1 \%$ of the doctorates in engineering, but in 2006 they earned $20 \%$ of those doctorates (National Science Foundation, 2008). Women also increasingly are assuming academic faculty positions in engineering. Although women comprised

\footnotetext{
*Correspondence concerning this article should be addressed to Laura Smart Richman, Department of Psychology and Neuroscience, Duke University, Durham, NC 27708 [e-mail: lrichman@duke.edu].

This research was supported by a NSF Advance Program Award (SBE-05-48323). Many thanks to Michelle Patriquin for her technical assistance with data collection.
} 
less than $1 \%$ of tenure-track or tenured engineering faculty through 1979, they increased to $11 \%$ of engineering faculty in 2006 (National Science Foundation, 2008). Yet, these gains are smaller at the higher levels of the academy, with women making up only $5 \%$ of the full professors in engineering in 2006 . This overall pattern typifies women's inroads into math-intensive science fields: Despite the substantial increase over the past half century, women are still a distinct minority, especially in higher status positions.

The changing role of women in science thus has several faces. On the downside, women continue to be in the minority. On the upside, women's increasingly greater entry and success indicates that some women are coping effectively with their minority status in math-intensive science and engineering fields. How do they do it? What are the factors that enable some women to be relatively impervious to the threats of being a minority in a traditionally male-dominated field?

In the present article, we address these questions by identifying sources of resilience for women academics, including freedom from discrimination, helpful female role models, and social support outside of work. Thus, our focus is not on whether identity threat occurs-this already has been well documented. Instead, we are trying to understand how some women succeed despite this threat. Specifically, we report the results of an experimental study testing the buffering factors that help women academics to cope with exposure to the identity threat of being in a numerical minority in a professional setting. By examining how successful women academics thrive despite their minority status, we highlight ways to develop measures and methods to promote women's success under such circumstances.

\section{Challenges for Women in Science and Engineering}

The challenges that women experience in science and engineering fields have fascinated college presidents and researchers alike (Ceci \& Williams, 2007; Halpern et al., 2007). These challenges include men's possibly greater aptitude for certain math skills (Hedges \& Nowell, 1995, although see Hyde, Lindberg, Linn, Ellis, \& Williams, 2008) and women's preference to study people as opposed to men's preference to study things (Lippa, 2005).

Other challenges women face stem from structural features in science and engineering fields, especially the low numerical representation of women. Being a numerical minority in work settings can activate gender stereotypes. Sex is one of the most visible social categories at work (Eagly \& Carli, 2008), and it becomes perceptually salient and is used in social categorization especially when one sex is in the numerical minority in a group (Kanter, 1977; Taylor \& Fiske, 1978).

A numerical minority position, by activating gender stereotypes, poses a particular threat to the identity of women scientists and engineers because it highlights expectations of men's performance advantage in a culturally masculine domain 
(Eagly \& Carli, 2008). Women scientists and engineers, in trying to grapple with the negative stereotype about their social identity, experience a situational burden that interferes with their performance. In fact, numerical distinctiveness is a common manipulation in experiments to activate stereotypic performance expectations and thus stereotype threat (Steele, 1997). For example, women performed worse at a difficult math test when they were the solo female in a group of men (Ben-Zeev, Fein, Inzlicht, 2005; Chatman, Boisnier, Spataro, Anderson, \& Berdahl, 2008; Inzlicht \& Ben-Zeev, 2000). This performance deficit was not found when sex ratios were more favorable to women or when the test assessed verbal skills (Chatman et al., 2008; Inzlicht \& Ben-Zeev, 2000). Even anticipating being a token woman in a work group can induce negative expectations about the experience (Cohen \& Swim, 1995).

At essence, the threat to self-integrity experienced by many women engineers stems from a state of cognitive imbalance in which women's concept of self and expectations for success conflict with primed social stereotypes of low competence at relevant tasks (Schmader, Johns, \& Forbes, 2008). That is, women scientists and engineers are faced with the cognitive imbalance from the following propositions: Women generally are not skilled at math and science; I am a woman; I am skilled at math and science. This state of imbalance is a stressor that impairs performance by activating physiological markers of stress, cognitive deficits, negative affect, and efforts to cope with these aversive experiences (e.g., Lord \& Saenz, 1985).

Thus, women's numerical minority status in traditionally masculine fields is a structural barrier that activates gender stereotypes and thereby poses a social identity threat. Some women resolve this imbalance by accepting that they are not skilled and do not belong in the relevant work setting. That is, women could limit their participation in these fields, especially in settings that precipitate threat. For example, female undergraduate math, science, and engineering majors expressed less desire to attend a professional conference depicted with more men than women than a conference with an equal sex ratio (Murphy, Steele, \& Gross, 2007). Nonetheless, some women become successful in these fields. These individuals are the focus of the present research. We seek to understand how these successful women reduce the experience of social identity threat.

\section{Resilience to Being a Numerical Minority}

Women scientists and engineers have several potential avenues to resolve the identity threat sparked by their numerical minority status in a traditionally masculine field. One way to resolve this threat is to focus on experiences that imply belongingness. Specifically, women engineers who have professional experiences indicating that they are valued and accepted in the engineering profession are likely to believe that, regardless of the stereotypes, they belong in the field. As we explain below, the experience of not being discriminated against and receiving fair treatment in comparison with others, having a positive female role model, and 
having social support is likely to establish such beliefs. These experiences might thus be the key to buffering the social identity threat faced by women in masculine fields.

\section{Experience of Discrimination}

Personal experiences of fair treatment and the absence of discrimination might increase women's sense of belonging in a field. Most of the relevant evidence has focused on the debilitating effects of discrimination and unfair treatment. Illustrating this negative impact, the mere suggestion of sexism caused women to feel less comfortable and to perform worse on a logic test than when sexism was not implied (Adams, Garcia, Purdie-Vaughns, \& Steele, 2006). Additional evidence of the debilitating effects of discrimination comes from the experience of racial and ethnic minorities. For example, minority adolescents' exposure to discrimination from teachers and friends at school was associated with lower grades and academic self-concept (Wong, Eccles, \& Sameroff, 2003) and discrimination also predicts broader effects on self-regulation capacity (Pascoe \& Richman, 2011). Although this research has focused on the debilitating effects of discrimination, it is possible also that fair treatment and the absence of discrimination have positive effects by heightening feelings of belonging.

\section{Female Role Models}

Female role models who demonstrate that women can be successful and who support other women's success also contribute to feelings of belongingness. In an illustration of the importance of female role models in academic settings, female junior faculty members who received mentoring from senior women had stronger academic self-concepts and higher rates of retention, grant funding, and promotion than those who did not receive such mentoring (Gardiner, Tiggemann, Kearns, \& Marshall, 2007). A female role model is particularly influential in performance domains where negative gender stereotypes exist. For example, when female students who were skilled in math took a difficult math test, the salience of female role models who were competent at math reduced the experience of social identity threat and bolstered women's self-appraised math ability (Marx \& Roman, 2002). Additionally, women who reported being influenced positively by role models in their training had higher career aspirations in science, technology, engineering, and math fields (Nauta, Epperson, \& Kahn, 1998).

\section{Social Support}

The social support provided by others is a general protective factor that may promote self-worth in conditions of social identity threat. When such threats occur, social support can provide a sense of belonging and access to emotional 
and tangible benefits such as people whom they feel close to and can turn to for guidance and assistance when needed. Social support is related to better achievement outcomes among minority groups (Walton \& Cohen, 2007), and evidence suggests that family encouragement and the perceived availability of social support influences the educational and occupational choices women make (Eccles, 1994; see also Syed, Azmitia, \& Cooper, 2011).

\section{The Present Research}

The present research examined how successful female engineering faculty cope with the social identity threat of being a numerical minority in this traditionally masculine field. To activate the experience of identity threat, participants watched a slide presentation describing an upcoming professional conference supposedly in their field based on Murphy et al. (2007). In the predominantly male (gender-imbalanced) condition, most of the conference attendees were male, and other cues indicated that the conference was designed for men (e.g., extracurricular activities were baseball and golf). The gender equal (gender-balanced) condition provided a more balanced representation of women and men, and cues to the conference were not strongly gender typed (e.g., extracurricular activities were an art museum and golf). We compared women engineers' responses to this stereotype threat experience with a control group of similar academic women from more gender-balanced academic fields (e.g., sociology, psychology).

Successful women academics in engineering are likely to have developed a certain level of resilience to social identity threat, as evidenced by their presence in this traditionally masculine field. Thus, we predicted that successful academic women engineers would be less sensitive to social identity threat than women from more gender-balanced fields and would be less likely to resolve the inconsistency of a male-dominated conference by deciding not to attend. Thus, our central prediction was a significant interaction between type of conference and disciplinary field on ratings of belonging at, and interest in the conference. This resilience to threat among engineers is likely to arise from personal experiences that suggest that they, personally, belong in the field. Thus, in predicting belongingness and interest, we anticipated significant interactions between gender balance of conference, disciplinary field, and buffering factors of lack of discrimination and positive female role models. This interaction should reflect that female engineers with these experiences have a stronger sense of belonging at, and are more interested in attending the predominantly male conference than engineers without these experiences. Additionally, social support is a general protective factor that may promote a sense of belongingness and self-worth for both engineers and nonengineers. Thus, we anticipated a significant interaction between extent of social support and gender balance of conference that held across disciplines. 


\section{Method}

\section{Participants}

Participants were female academics in the field of engineering $(N=31)$ or in control, nonengineering fields $(N=27)$ selected to have relatively genderbalanced faculty ratios (i.e., psychology, sociology, anthropology, nursing, history, English). Recruitment was done via e-mails, advertisements placed in academic buildings, and during an engineering conference. Participants received \$20 for their time.

\section{Procedure}

Prior to the experimental session, participants completed an online survey assessing background characteristics. They reported on their past discrimination, experience with female role models, and extent of social support.

During the laboratory session, participants watched a 5-minute video (adapted from Murphy et al., 2007) advertising a fictitious upcoming academic conference describing where the conference would be held, procedures for admission, and professional activities. The specific discipline of the conference was ambiguous so that all participants could identify with the video. In the gender-balanced condition, the video portrayed equal numbers of males and females, and the social activities included golfing and a tour of art museums. In the gender-imbalanced condition, males outnumbered females 5:1, and the social activities included golfing and a tour of a local baseball stadium. Participants gave their reactions to the video (see below).

\section{Measures}

Past discrimination. On the Everyday Discrimination Scale (Williams, Yu, Jackson, \& Anderson, 1997), participants indicated on 4-point scales ranging from never (1) to often (4) the extent to which they perceived nine different forms of discrimination in the past 12 months. Example items include, "People act as if you are less intelligent than you are," and "You receive poorer service than others in restaurants or stores." Mean scores were calculated across the nine items. Internal consistency on the scale in our sample was high, $\alpha=.88$.

Female role models. On a 5-point scale from none to a great deal, participants indicated how much contact they had with female role models. Also, on a 5-point scale from very negative (1) to very positive (5), participants indicated whether this contact was negative or positive. 
Social support. To assess family support, we asked participants "how encouraging was your family about your chosen field of study?" Responses were given on a 5-point scale anchored by very discouraging (1) and very encouraging (5).

An adapted version of the Interpersonal Support Evaluation List (Cohen \& Hoberman, 1983) was used to measure social support on the dimensions of belonging (perceived availability of someone to do things with), appraisal help (perceived availability to talk with someone about problems), tangible support (perceived availability of material help), and self-esteem support (perceived availability of someone to positively compare oneself with). Participants rated 16 statements from definitely false (1) to definitely true (4). Overall social support was computed by taking the average of these items. Internal consistency on the scale in our sample was high, $\alpha=.89$.

Reactions to conference. On six items, participants were asked to indicate their sense of belongingness and interest regarding the conference. Three items measured belongingness (e.g., "I feel like I would belong at this conference;" alpha $=.88)$, and three items measured interest in attending the conference (e.g., "I would be interested in attending the conference;" alpha = .96). Each item was presented on a 5-point scale ranging from definitely disagree (1) to definitely agree (5).

\section{Results}

\section{Background Differences between Engineers and Nonengineers}

As shown in Table 1, women faculty in engineering, compared with nonengineering women faculty, reported slightly more experiences of unfair treatment in the past 12 months $(p=.06)$. Women engineers also reported great social support

Table 1. Descriptive Statistics, Scale Reliability and Group Differences of Individual Difference and Psychosocial Variables

\begin{tabular}{lcc}
\hline Measure & $\begin{array}{c}\text { Engineers } \\
M(S D)\end{array}$ & $\begin{array}{c}\text { Nonengineers } \\
M(S D)\end{array}$ \\
\hline Past discrimination & $2.13(0.50)$ & $1.90(0.50)$ \\
Contact with female role models & $2.58(1.15)_{\mathrm{a}}$ & $3.48(1.50)_{\mathrm{b}}$ \\
Positivity of female role models & $3.60(1.25)$ & $3.81(1.25)$ \\
Social support & $1.82(0.51)_{\mathrm{a}}$ & $1.55(0.37)_{\mathrm{b}}$ \\
Family support & $4.12(1.11)$ & $4.03(1.21)$ \\
Years since PhD & $7.10(3.61)_{\mathrm{a}}$ & $11.50(6.50)_{\mathrm{b}}$ \\
\hline
\end{tabular}

Note. Means with differing subscripts are significantly different $(p<.05)$. 
Table 2. Reported Belonging at, and Interest in Attending the Conference by Field and Conference Description

\begin{tabular}{lccccc}
\hline & \multicolumn{2}{c}{ Engineers } & & \multicolumn{2}{c}{ Nonengineers } \\
\cline { 2 - 3 } \cline { 5 - 6 } & $\begin{array}{c}\text { Gender equal } \\
M(S D)\end{array}$ & $\begin{array}{c}\text { Predominantly male } \\
M(S D)\end{array}$ & & $\begin{array}{c}\text { Gender equal } \\
M(S D)\end{array}$ & $\begin{array}{c}\text { Predominantly male } \\
M(S D)\end{array}$ \\
\hline Belonging & $3.96(0.85)$ & $3.96(0.84)$ & & $4.18(1.11)$ & $3.17(1.17)$ \\
Interest & $3.88(1.22)$ & $3.56(1.04)$ & & $4.15(0.96)$ & $2.69(1.34)$ \\
\hline
\end{tabular}

outside of work and less contact with female role models in their graduate training $(p s<.05)$. On average, female nonengineers held their doctorate degrees for longer than the female engineers $(p<.05)$. Women engineers were comparable to the nonengineers in the positivity of their experiences with female role models and in family support for their careers.

\section{Reactions to the Conference}

To test our hypothesis about reactions to social identity threat, we analyzed received belongingness ratings with Conference Type (equal vs. predominately male) $\times$ Disciplinary Field (engineering vs. nonengineering) analysis of variance. In all the models, we analyzed the outcomes of belonging and interest separately because, even though they have comparable effects across all the analyses, they each provide unique insight into the factors that moderate social identity threat.

The predicted interaction approached significance, $F(1,54)=3.72, p=.06$. As can be seen in Table 2, engineering women faculty did not respond differently to the gender-balanced versus male-dominated conference $(F<1)$. However, women faculty from nonengineering fields reported significantly less belongingness when the conference was male-dominated than when it was balanced, $F(1,54)=5.28$, $p<.05$. Similarly, in the analysis on how interested participants were in attending the conference, the interaction between field and video condition approached significance, $F(1,54)=3.55, p=.06$. Again, engineers' interest in attending the conference was not influenced by whether it was portrayed as balanced or imbalanced $(F<1)$, but nonengineers were significantly less likely to be interested in attending a gender-imbalanced than a gender-balanced conference, $F(1,54)=$ $10.44, p<.01$.

\section{Moderators of Identity Threat}

To examine whether positive experiences with female role models and lack of discrimination buffered social identity threat, we constructed regression models in 
Table 3. Correlations between Perceived Discrimination (PD), Social Support, and Female Role Models

\begin{tabular}{lccc}
\hline & $\begin{array}{c}\text { Perceived } \\
\text { discrimination }\end{array}$ & $\begin{array}{c}\text { Social } \\
\text { support }\end{array}$ & $\begin{array}{c}\text { Positivity of female } \\
\text { role models }\end{array}$ \\
\hline Social support & $0.23^{*}$ & & \\
Positivity of female role models & $-0.29^{* *}$ & -0.15 & $0.37^{* * *}$ \\
Family support & $-0.37^{* * *}$ & -0.07 & \\
\hline
\end{tabular}

Note. ${ }^{*} p<.10,{ }^{* *} p<.05,{ }^{* * *} p<.01$.

which predictors that were continuous variables were standardized and interaction terms were computed between predictors. Table 3 shows the correlations between these variables. Following the suggestions of Cohen, Cohen, Aiken and West (2003), we interpreted the interactions by estimating simple slopes at one standard deviation below and one standard deviation above the mean of each moderator. Because of a priori predictions and our small sample size, we examined all simple slopes regardless of whether the overall interactions were significant.

Perceived discrimination. In support of our hypotheses, women engineers who perceived fair treatment in the past were less susceptible to social identity threat and reported a greater sense of belonging to the predominantly male conference than did those with higher levels of perceived discrimination, $t(53)=-2.46$, $p<.05$ (see Figure 1). Perceived discrimination did not influence reactions to the gender-equal conference by engineers or reactions to either conference by nonengineers (all $t \mathrm{~s}<1$ ).

Positive experiences with female role models. In partial support of our predictions, having positive experiences with female role models did not buffer women from social identity threat, but not having positive experience was a vulnerability and increased negative responding to the threat. After controlling for overall contact with female role models, women engineers with less positive experiences with female role models expressed marginally less interest in attending a conference when it was represented as male dominated as compared to when it was gender balanced, $t(44)=-1.54, p<.10$ (see Figure 2). Engineers with more positive experiences with female role models did not respond differently to the balanced and imbalanced videos and nonengineers were more interested in attending the balanced conference, regardless of role model influence.

Social support. We anticipated that social support would be a generally ameliorative factor that promoted well-being and thereby buffered challenges for both engineers and nonengineers. As Figure 3 shows, this prediction held for the amount 
Nonengineers

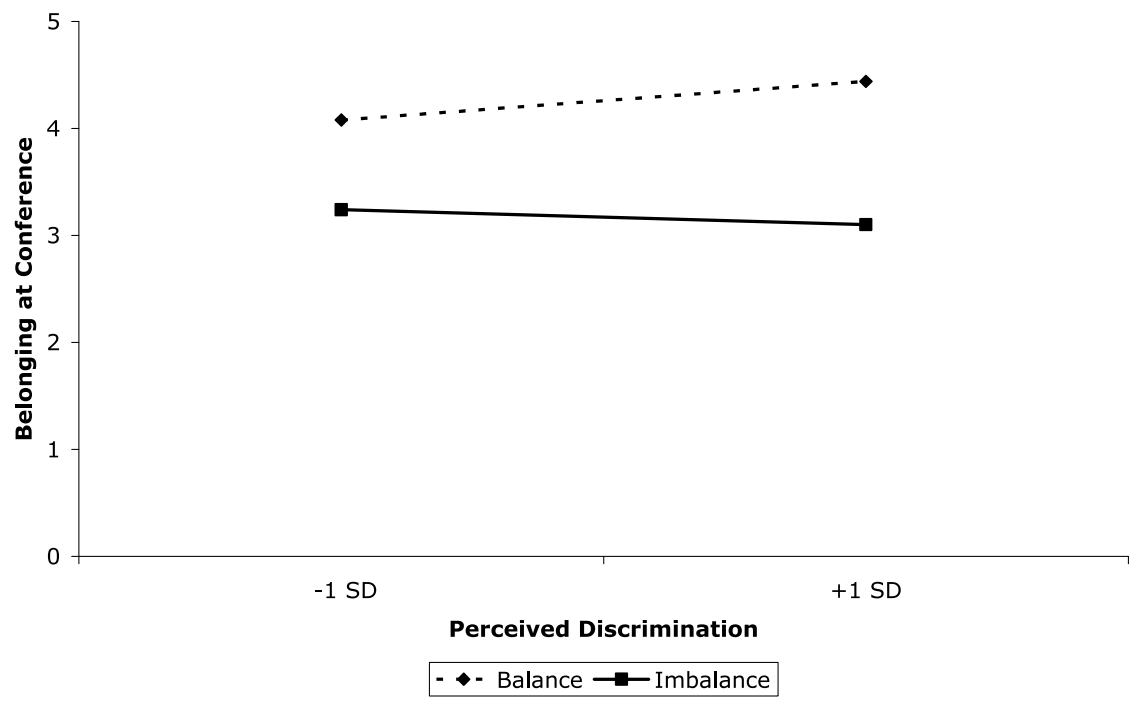

Engineers

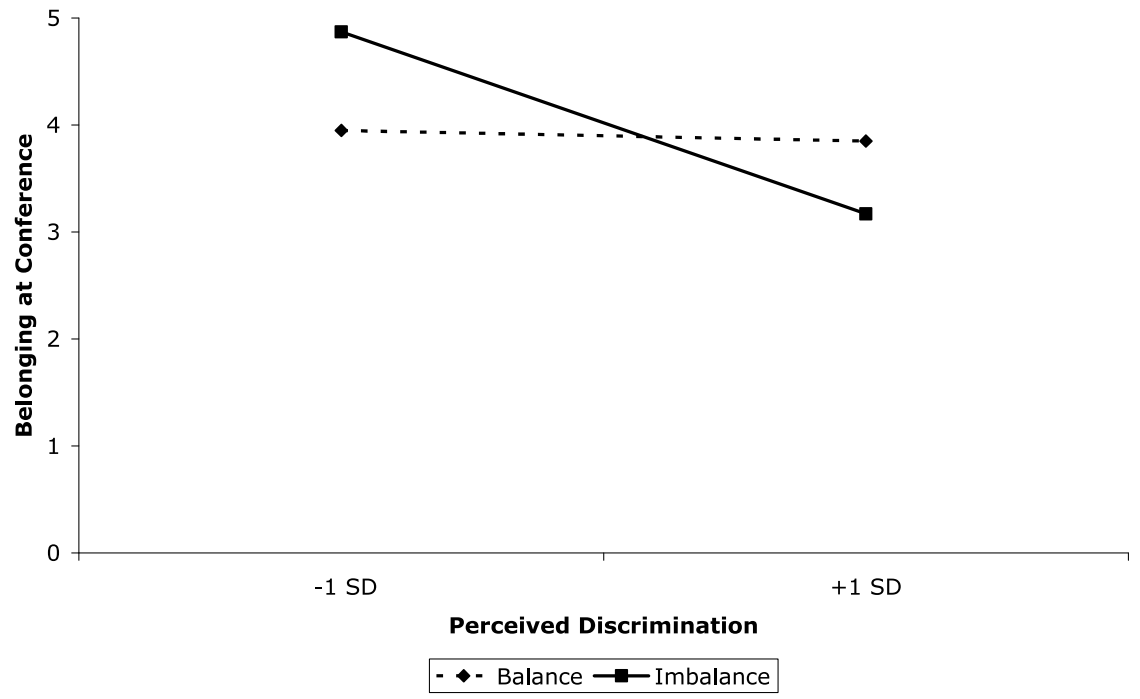

Fig. 1. Perceived belongingness at the conference as a function of field, gender balance of conference, and experiences with discrimination. 
Nonengineers

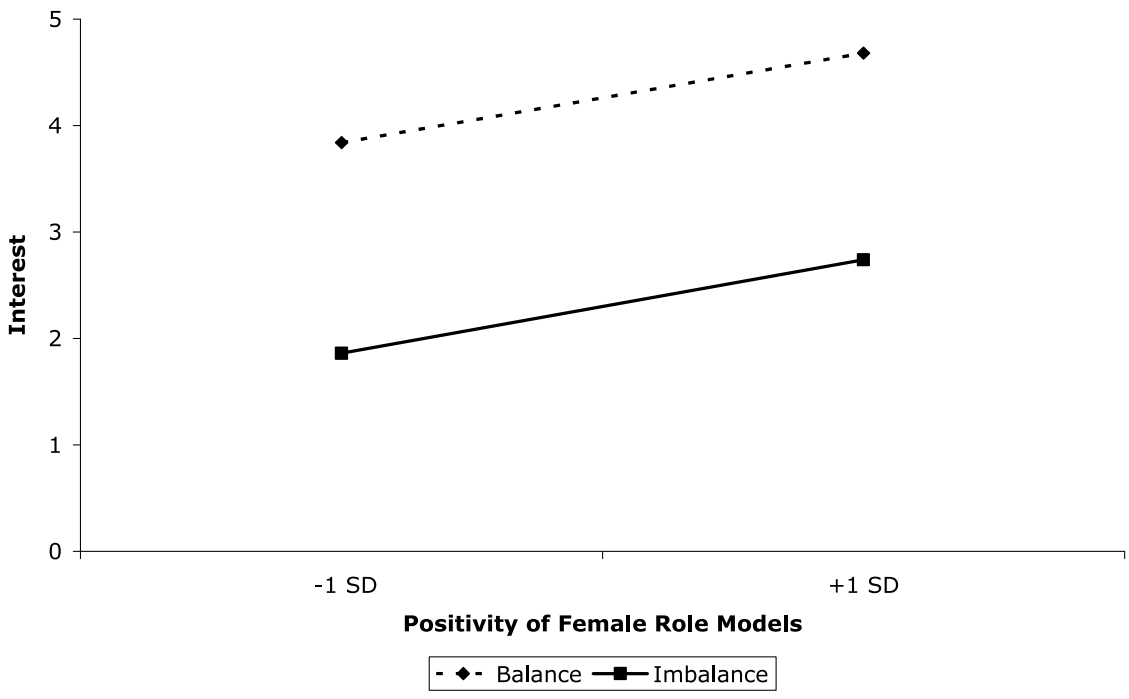

Engineers

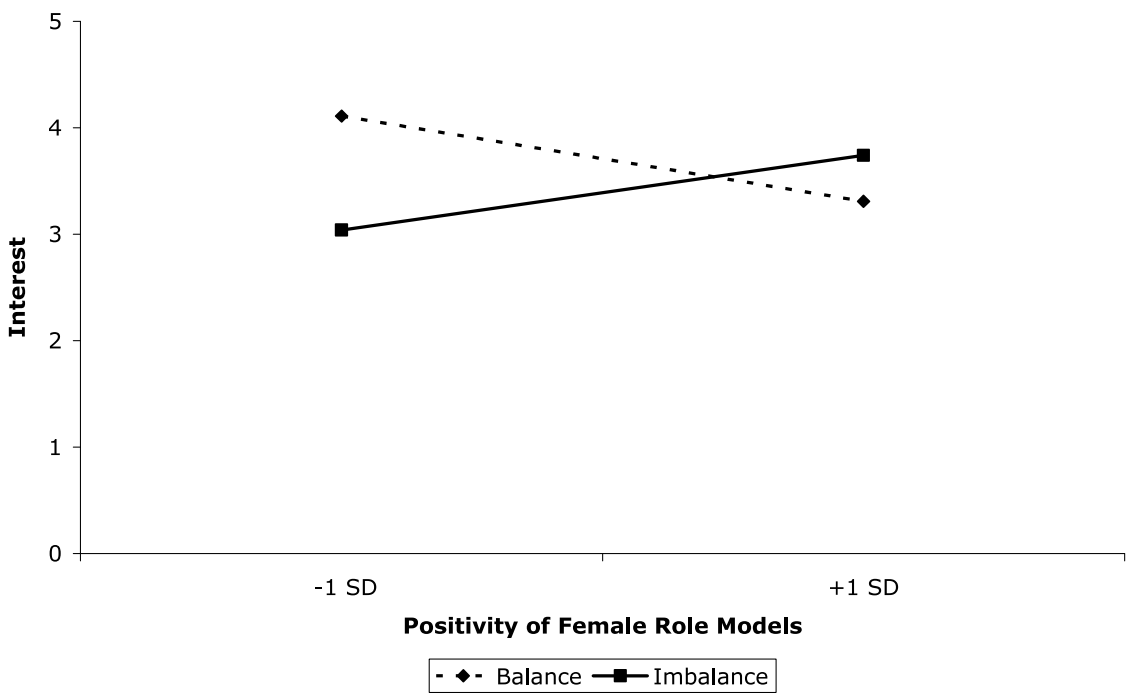

Fig. 2. Interest in attending the conference as a function of field, gender balance of conference, and positivity of interactions with female role models. 


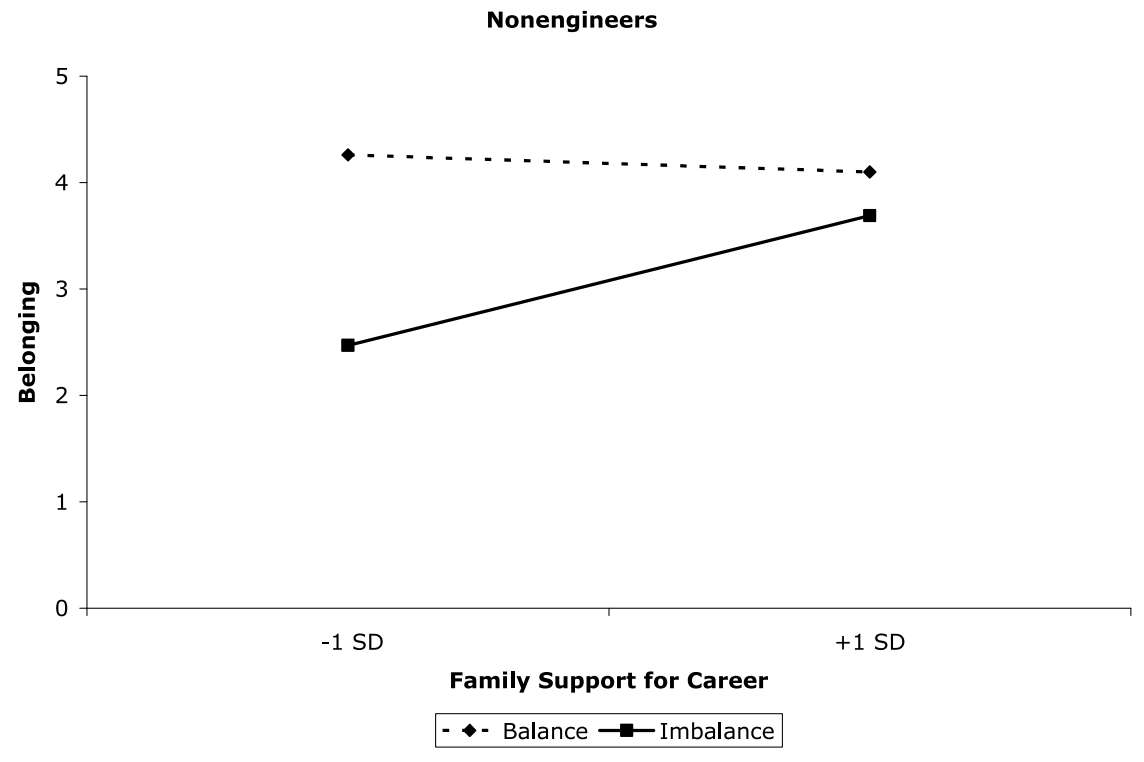

Engineers

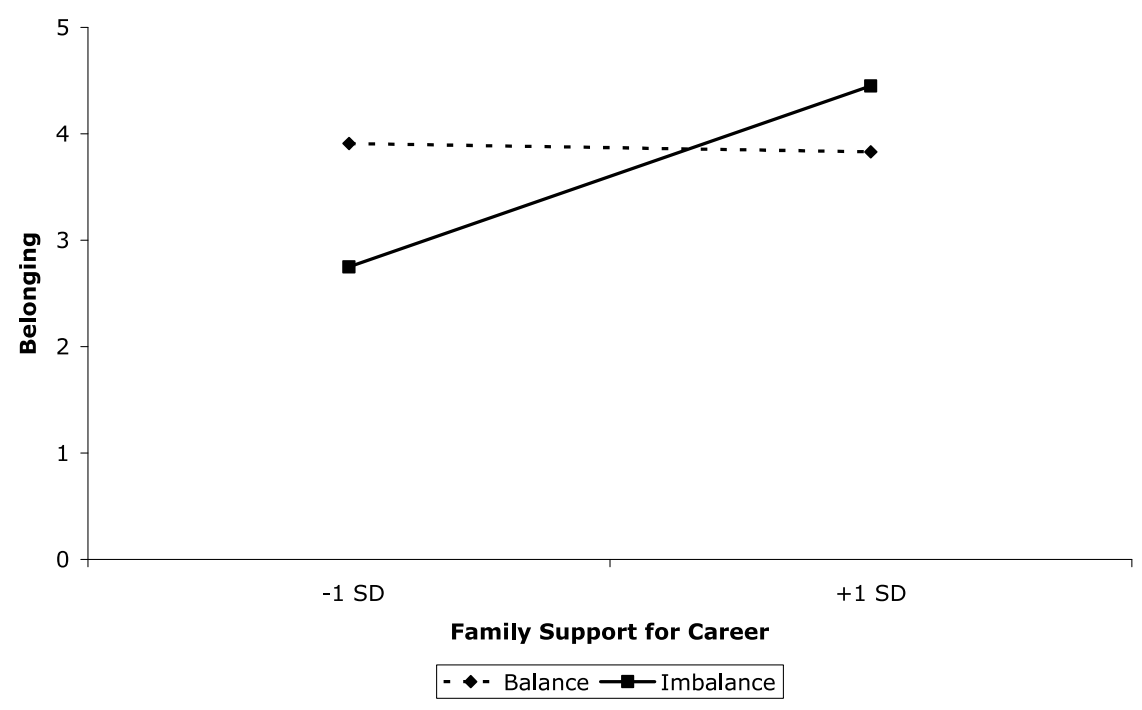

Fig. 3. Perceived belongingness at the conference as a function of field, gender balance of conference, and family support for field of study. 
of family support for one's chosen career. Participants with higher levels of family support reported a greater expectation of belonging at the predominantly male conference than did those with lesser family support, and this effect held for engineers, $t(53)=2.16, p<.05$, and nonengineers, $t(53)=2.09, p<.05$. Family support did not influence responses to the gender equal conference for either group (all $F \mathrm{~s}<1$ ). Our prediction also held for general social support (see Figure 4). Participants with low levels of social support were less interested in attending the conference if it was portrayed as male dominated rather than gender equal. This was consistent for both engineers (marginally), $t(53)=1.61, p<.08$ and nonengineers, $t(53)=3.10, p<.01$. At high levels of social support, interest in attending the conference did not differ according to gender ratio portrayed in the video $(F \mathrm{~S}<1)$.

\section{Discussion}

The central finding from this research is that academic women in the field of engineering were less reactive to the experience of social identity threat than were academic women from more gender-balanced fields. The women engineers' sense of belonging at, and interest in attending a professional conference were not influenced by the numbers of women portrayed at the conference, whereas the nonengineering women reported a reduced sense of belonging and less interest in attending a male-dominated rather than gender-balanced conference. The successful women engineers in our sample appear to have developed means of coping with the social identity threat that arises from their minority status in the field. In addition, certain academic and social experiences of these women were important moderators of whether their social identity was threatened.

For the women engineers, a history of fair treatment and minimal perceived exposure to discrimination was related to a decreased vulnerability to social identity threat. Engineering women who perceived less exposure to discrimination in the past year reported feeling more belonging at the male-dominated conference compared with those who perceived more exposure to discrimination. The nonengineers, in contrast, reported less belonging at the male-dominated conference, regardless of their perceived discrimination. This effect suggests an important qualification of the responses to the different videos. It is not simply that the engineering women had more experience with being in gender-imbalanced environments and were therefore relatively more comfortable in attending a predominantly male conference. Rather, the absence of perceived discrimination was related to the engineers' comfort at the male-dominated conference. Past research has found that experiences of observing the underrepresentation of women in a field and experiences with being a target of repeated, subtle discrimination can lead to a state of belonging uncertainty (Walton \& Cohen, 2007) that impairs 
Nonengineers

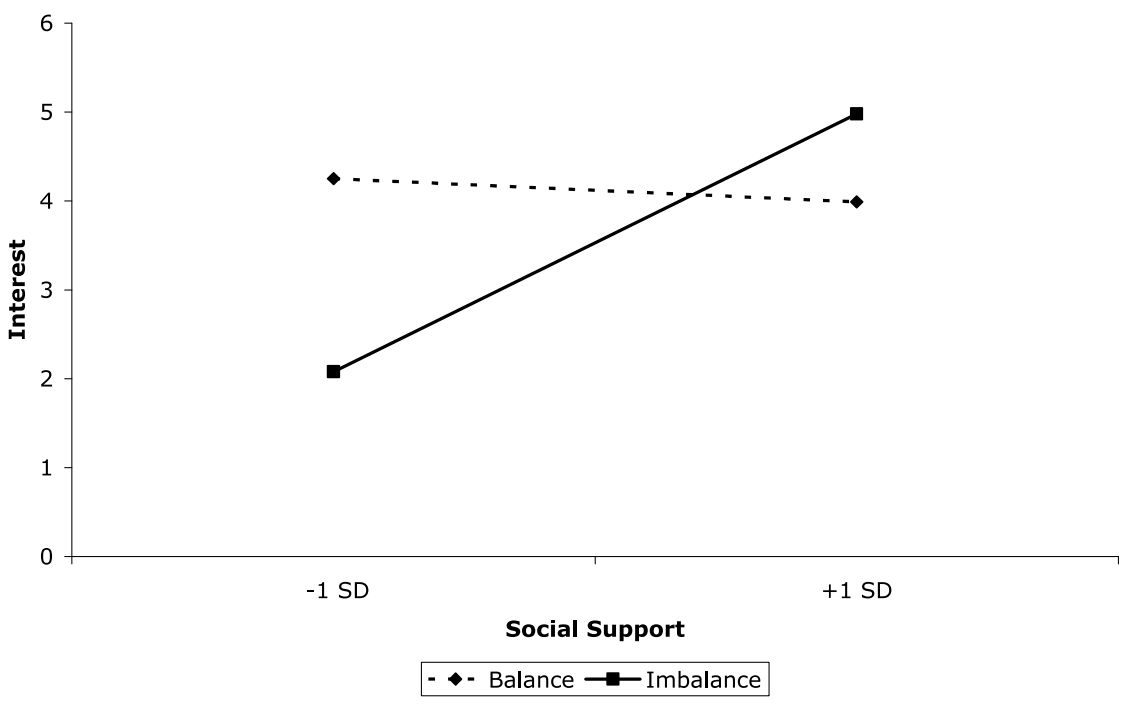

Engineers

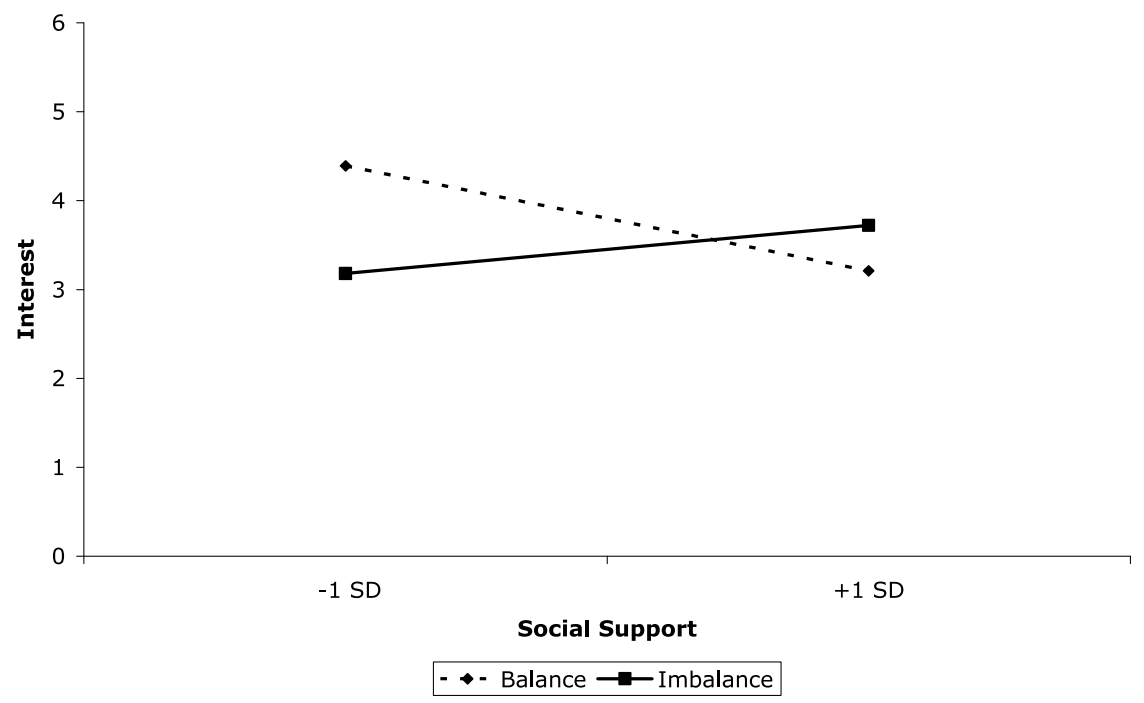

Fig. 4. Interest in attending the conference as a function of field, gender balance of conference, and social support. 
achievement and motivation of underrepresented groups in academic settings. Our findings imply that working in environments where one perceives fair treatment can promote women's experience of belonging and engagement in similar environments in the future.

The absence of positive female role models also affected how women in engineering appraised the threat. Women engineers with less experience with positive female role models were marginally less interested in attending the predominately male, as compared to the gender-balanced conference. This effect suggests that the lack of supportive female role models heightens the threat in gender-imbalanced work environments.

For all of the women in our study, supportive social networks were important elements to success in an identity threatening environment. Having a strong support network encourages feelings of belonging and appraisals of intimacy and thereby contributes to an increased sense of interest and inclusiveness in the face of a potential social identity threat. We also found that for both groups of women, strong perceptions of the availability of social support provided a buffer to the experience of social identity threat. Typically, past research has focused on social support as an adaptive coping mechanism in response to social identity-based stressors. For example, people who have more social support after experiencing a social identity threat have better emotional and physical outcomes (e.g., Richman, Bennett, Pek, Siegler, \& Williams, 2007). However, our findings suggest that perceived social support may also influence how people appraise a threatening environment. We found that both groups of women evaluated the threat as less severe when they considered themselves to have strong support networks. Future research would benefit from examining how these perceptions could in turn lead to a greater willingness to enter gender-imbalanced academic settings that hold the potential to be threatening environments.

Social support in the form of family encouragement for their chosen careers also was a positive buffer for both groups of women. This finding is consistent with the parent socialization model (Eccles, Adler, \& Kaczala, 1982) in which the expectations that parents have of their children's future careers influence children's motivation to pursue these fields. For example, daughters of parents who hold egalitarian gender role attitudes maintain high levels of math and science achievement in adolescence. In a test of this model, Chhin, Bleeker, and Jacobs (2008) found that across three studies, parents' beliefs and expectations reported when their children were adolescents played an important role in shaping their children's gender-typed occupational choices during young adulthood. This research emphasizes that family support and encouragement in both traditional and nontraditional occupational domains enables women to be better able to cope with negative socialization pressures and social identity threat. 


\section{Conclusion}

In summary, women in the field of engineering on average have developed the capacity to cope with their minority status in their predominantly male field and the stereotypic perceptions that are activated in such contexts. Thus, they were more likely to feel that they belonged in a male-dominated conference than women from more gender-balanced academic fields. The engineers were especially able to cope with social identity threat when they had experiences to suggest that they, personally, belonged in such settings. These included a history of minimal personal discrimination and a history of positive female role models. Women engineers without these buffering experiences reacted to the threat with reduced interest in attending the conference, and were in this way similar to the nonengineers.

Our findings indicate that efforts to reduce discrimination, provide positive female role models, and establish social support in traditionally male academic settings have meaningful implications for women's willingness to pursue and persist in these environments. This research also underscores the importance of fostering the careers of women in science, match, and technology fields to increase the likelihood that girls and women will stay in the pipeline. These efforts could then lead to an upward trend in which more women are available to serve as effective role models for future women during their training and careers, which could then encourage more women to seek out and flourish in these environments.

\section{References}

Adams, G., Garcia, D. M., Purdie-Vaughns, V., \& Steele, C. M. (2006). The detrimental effects of a suggestion of sexism in an instruction situation. Journal of Experimental Social Psychology, 42, 602-615. doi:10.1016/j.jesp.2005.10.004.

Ben-Zeev, T., Fein, S., Inzlicht, M. (2005). Arousal and stereotype threat. Journal of Experimental Social Psychology, 41, 174-181. doi:10.1016/j.jesp.2003.11.007.

Ceci, S. J., \& Williams, W. M. (Eds.). (2007). Why aren't more women in science? Top researchers debate the evidence. Washington, DC: American Psychological Association.

Chatman, J. A., Boisnier, A. D., Spataro, S. E., Anderson, C., \& Berdahl, J. L. (2008). Being distinctive versus being conspicuous: The effects of numeric status and sex-stereotyped tasks on individual performance in groups. Organizational Behavior and Human Decision Processes, 107, 141 - 160. doi:10.1016/j.obhdp.2008.02.006.

Chhin, C. S., Bleeker, M. M., \& Jacobs, J. E. (2008). Gender-typed occupational choices: The longterm impact of parents' beliefs and expectations. In H.M G. Watt and J. S. Eccles (Eds.), Gender and occupational outcomes. Washington, DC: APA.

Cohen, S., \& Hoberman, H. M. (1983). Positive events and social support as buffers of life change stress. Journal of Applied Social Psychology, 13, 99-125. doi:10.1111/j.1559-1816.1983.tb02325.x.

Cohen, L. L., \& Swim, J. K. (1995). The differential impact of gender rations on women and men: Tokenism, self-confidence, and expectations. Personality and Social Psychology Bulletin, 21, 876-884. doi:10.1177/0146167295219001.

Cohen, J., Cohen, P., West, S. G., \& Aiken, L. S. (2003) Applied multiple regression/correlation analysis for the behavioral sciences (3rd ed.). Mahwah, NJ: Erlbaum. 
Eagly, A. H., \& Carli, L. L. (2008). Through the labyrinth: The truth about how women become leaders. Boston, MA: Harvard University Press.

Eccles, J. (1994). Understanding women's educational and occupational choices: Applying the Eccles et al. model of achievement-related choices. Psychology of Women Quarterly, 18, 585-609. doi:10.1111/j.1471-6402.1994.tb01049.x.

Eccles, J., Adler, T. F., \& Kaczala, C. M. (1982). Socialization of achievement attitudes and beliefs: Parental influences. Child Development, 53, 322-339. doi:10.2307/1128973.

Gardiner, M., Tiggemann, M., Kearns, J., \& Marshall, K. (2007). Show me the money! An empirical analysis of mentoring outcomes from women in academia. Higher Education Research \& Development, 26, 425-442. doi:10.1080/07294360701658633.

Halpern, D. F., Benbow, C. P. Geary, D. C., Gur, R. C., Hyde, J. S., \& Gernsbacher, M. A. (2007). The science of sex differences in science and mathematics. Psychological Science in the Public Interest, 8, 1-51. doi:10.1111/j.1529-1006.2007.00032.x.

Hedges, L. V., \& Nowell, A. (1995). Sex differences in mental test scores, variability, and numbers of high-scoring individuals. Science, 269, 41-45. doi:10.1126/science.7604277.

Hyde, J., Lindberg, S. M., Linn, M. C., Ellis, A. B., \& Williams, C. C. (2008). Gender similarities characterize math performance. Science, 321, 494-495. doi:10.1126/science.1160364.

Inzlicht, M., \& Ben-Zeev, T. (2000). A threatening intellectual environment: Why females are susceptible to experiencing problem-solving deficits in the presence of males. Psychological Science, 11,365-371. doi:10.1111/1467-9280.00272.

Kanter, R. (1977). Men and women of the corporation. New York: Basic Books.

Lippa, R. A. (2005). Gender, nature, and nurture. Mahwah, NJ: Erlbaum.

Lord, C. G., \& Saenz, D. S. (1985). Memory deficits and memory surfeits: Differential cognitive consequences of tokenism for tokens and observers. Journal of Personality and Social Psychology, 49, 918 -926. doi:10.1037/0022-3514.49.4.918.

Marx, D. M., \& Roman, J. S. (2002). Female role models: Protecting women's math test performance. Personality and Social Psychology Bulletin, 28, 1183-1193. doi:10.1177/01461672022812004.

Murphy, M. C., Steele, C. M., \& Gross, J. J. (2007). Signaling threat: How situational cues affect women in math, science, and engineering settings. Psychological Science, 18, 879-885. doi:10.1111/j.1467-9280.2007.01995.x.

National Science Foundation. (June, 2008). Thirty-three years of women in S\&E faculty positions. Arlington, VA: National Science Foundation, Division of Science Resources Statistics. http://www.nsf.gov/statistics/infbrief/nsf08308/, accessed on line June 23, 2009.

Nauta, M. M., Epperson, D. L., \& Kahn, J. H. (1998). A multiple-groups analysis of predictors of higher level career aspirations among women in mathematics, science, and engineering majors. Journal of Counseling Psychology, 45, 483-496. doi:10.1037/0022-0167.45.4.483.

Pascoe, E., \& Richman, L. S. (2011). Effects of discrimination on food decisions. Self and Identity, 10, 396-406. doi:10.1080/15298868.2010.526384.

Richman, L. S., Bennett, G., Pek, J., Siegler, I. C.. \& Williams, R. B. (2007). Discrimination, dispositions, and cardiovascular responses to stress. Health Psychology, 26, 675-683. doi: $10.1037 / 0278-6133.26 .6 .675$.

Schmader, T., Johns, M., \& Forbes, C. (2008). An integrated process model of stereotype threat effects on performance. Psychological Review, 115, 336-356. doi:10.1037/0033-295X.115.2.336.

Steele, C. M. (1997). A threat in the air: How stereotypes shape the intellectual identities and performance of women and African-Americans. American Psychologist, 52, 613-629. doi:10.1037/0003-066X.52.6.613.

Syed, M., Azmitia, M., \& Cooper, C. R. (2011). Identity and academic success among underrepresented ethnic minorities: An interdisciplinary review and integration. Journal of Social Issues, 67(3), 442-468.

Taylor, S. E., \& Fiske, S. T. (1978). Salience, attention and attribution: Top of the head phenomena. In L. Berkowitz (Ed.), Advances in experimental social psychology (Vol. 11. pp. 249-288). New York: Academic Press.

Walton, G. M., \& Cohen, G. L. (2007). A question of belonging: Race, social fit, and achievement. Journal of Personality and Social Psychology, 92, 82-96. doi:10.1037/0022-3514.92.1.82. 
Williams, D. R., Yu, Y., Jackson, J. S., \& Anderson, N. B. (1997). Racial differences in physical and mental health: Socioeconomic status, stress and discrimination. Journal of Health Psychology, 2, 335-351. doi:10.1177/135910539700200305.

Wong, C. A., Eccles, J. S., \& Sameroff, A. (2003). The influence of ethnic discrimination and ethnic identification on African American adolescent's school and socioemotional adjustment. Journal of Personality, 71, 1197-1232. doi:10.1111/1467-6494.7106012.

Wood, W., \& Eagly, A. H. (in press). Gender. In S. T. Fiske, D. T. Gilbert, \& G. Lindzey (Eds.), Handbook of social psychology (5th ed.).

LAURA SMART RICHMAN is an Assistant Professor of social and health psychology in the Department of Psychology \& Neuroscience at Duke University. Her research focuses on stress and coping processes associated with experiences of social inequality, with an emphasis on how perceived discrimination affects health-related behavior and outcomes.

MICHELLE VANDELLEN is a Franklin Postdoctoral Fellow at the University of Georgia. She received her PhD in Social Psychology from Duke University in 2008. Her research interests include how individuals manage threats to the self and how social and environmental factors influence self-control.

WENDY WOOD is Provost Professor of Psychology and Business at the University of Southern California. Her research interests are in gender, especially evolutionary origins of gender differences, and in habits and attitudes as determinants of behavior. She is a fellow of the American Psychological Association, the Association for Psychological Science, the Society for Experimental Social Psychology, and founding member of the Society for Research Synthesis Methodology. 